\title{
Cécile Joulin, La Mort dans les Oeuvres oratoires de Bossuet
}

\section{Benedetta Papasogli}

\section{Q OpenEdition}

1 Journals

\section{Edizione digitale}

URL: https://journals.openedition.org/studifrancesi/39292

DOI: 10.4000/studifrancesi.39292

ISSN: 2421-5856

\section{Editore}

Rosenberg \& Sellier

\section{Edizione cartacea}

Data di pubblicazione: 1 décembre 2004

Paginazione: $360-361$

ISSN: 0039-2944

\section{Notizia bibliografica digitale}

Benedetta Papasogli, «Cécile Joulin, La Mort dans les Oeuvres oratoires de Bossuet», Studi Francesi [Online], 143 (XLVIII | II) | 2004, online dal 30 novembre 2015, consultato il 19 mai 2021. URL: http:// journals.openedition.org/studifrancesi/39292 ; DOI: https://doi.org/10.4000/studifrancesi.39292

Questo documento è stato generato automaticamente il 19 mai 2021.

\section{(c) $(1) \&$}

Studi Francesi è distribuita con Licenza Creative Commons Attribuzione - Non commerciale - Non opere derivate 4.0 Internazionale. 


\title{
Cécile Joulin, La Mort dans les Oeuvres oratoires de Bossuet
}

\author{
Benedetta Papasogli
}

\section{NOTIZIA}

CÉCILE JOULIN, La Mort dans les Oeuvres oratoires de Bossuet, Saint Etienne publications de l'Université de Saint Etienne, 2002, p. 469.

1 Dedicare un ampio lavoro di tesi al tema della morte nell'opera di Bossuet può portare a ribadire quel'interpretazione che Chateaubriand ha reso celebre di Bossuet come "homme du tombeau», incessantemente occupato dagli abissi del nulla; oppure ad articolarla e sfumarla anche alla luce della messa in guardia di Jacques Truchet che in un suo noto articolo (del 1981) aveva vigorosamente ricusato di vedere nell'oratore delle Oraisons funèbres un «obsédé de la mort». L'argomento dello studio che presentiamo non è certo nuovo ma, anche a causa della ricchezza della sua tradizione critica, meritava una messa a punto esaustiva. Ci piace qui raccogliere le espressioni con cui l'autrice conclude la sua introduzione: «Bossuet écrivait, dans le Sermon sur la haine de la vérité, que «la simplicité et la bonne foi sont de grands docteurs qui laissent peu de choses indécises». Ce sont les deux grands docteurs que nous souhaitons prendre pour guide tout au long de ce travail» (p. 19) Semplicità e buona fede sono testimoniate ovunque dall'autrice, insieme col rigore di una ricerca coscienziosa, e traspaiono anche in quelle rare smagliature del testo cui il termine «ingenuità» si applicherebbe forse più propriamente.

2 Il volume si struttura in tre parti. La prima, dedicata a $L$ 'événement de la mort, rende evidente una sorta di cronologia interna all'evento: la preparazione, o «memento mori»; l'atto del morire, che si configura diversamente nella morte del giusto e nella morte dell'empio; il gudizio, "particolare» piuttosto che «universale», secondo la pastorale della morte tipica dell'età post-tridentina. La seconda indaga attraverso l'opera di Bossuet Le sens de la mort: senso morale, come «leçon de ténèbres»derivata 
soprattutto dalla morte dei grandi; sens teologico, in rapporto alla dottrina cristana del peccato e alla coscienza cristiana della finitezza del tempo; senso retorico, alla luce della domanda se esista nell'eloquenza di Bossuet, nutrita continuamente dal rapporto con la Scrittura, una particolare e originale retorica della morte. La terza parte - 0 mort où est ta victoire? - indica nella teologia cristiana della passione e della resurrezione il principio di un trascendimento dell'esperienza esistenziale del morire.

3 Appunto alla densità esistenziale del tema si richiama l'autrice, fin dalle pagine dell'introduzione, per stabilire col lontano mondo di Bossuet un contatto che non sia solo apprezzamento di uno splendore formale, ricezione estetica. Ed è suo merito, e contributo precipuo del suo lavoro, aver risuscitato intorno a Bossuet il dinamismo delle idee che nutrivano eloquenza, morale, letteratura del tempo, tessendo una rete di riferimenti intertestuali, cercando di cogliere il timbro della sua voce all'interno di una vasta polifonia in cui autori grandi e minori sono opportunamente chiamati in causa.

4 Accennavamo a qualche smagliatura di questo bel libro. Alcuni esempi: più volte citato, Grignion de Montfort sembra esser considerato il testimone di una generazione spirituale che precede Bossuet, mentre - com'è noto - è vissuto a cavallo tra Seicento e Settecento. Nello sforzo di rendere evidente la differenza tra teologia tridentina e teologia del Vaticano II, l'autrice incorre in semplificazioni poco felici o addirittura improprie. Più generalmente, il lettore può avvertire un disagio di fronte alla strutturazione stessa del lavoro. La terza parte, cristologica, pasquale, non avrebbe meritato di essere posta al centro di quella ricerca sul senso della morte - in particolare sul suo senso teologico - che strategicamente si sviluppa al cuore del volume? Si direbbe che il nucleo stesso della spiritualità cristiana entri in scena, in questo studio su Bossuet, con uno strano ritardo. C'è stato forse come un impaccio da parte dell'autrice nel maneggiare una materia interdipendente e complessa. 0 , con un rovesciamento favorevole, si può dire che il libro va letto fino all'ultima pagina, per scoprire il segreto di cui ha attizzato il desiderio e orchestrato ampiamente la ricerca. 